\title{
Frequency of Restrictive Pulmonary Function in Type 2 Diabetes Mellitus
}

\author{
Muhammad Farooq, ${ }^{1}$ Sheraz Saleem, ${ }^{2}$ Imtiaz Hussain, ${ }^{3}$ Sajid Abaidullah ${ }^{4}$
}

\begin{abstract}
Objectives: The aim of this study was to determine the frequency of restrictive pulmonary dysfunction in type 2 diabetic patients.

Study Design: Cross - sectional Study.

Setting: Outpatient clinic of Department of Medicine, King Edward Medical University, Lahore.

Subject and Methods: One hundred and seventy patients of Type 2 Diabetes Mellitus, presented in outpatient department of Mayo Hospital, Lahore with inclusion and exclusion criteria were included in the study. After taking informed consent, pulmonary function tests were performed. Patients were explained about the risks and benefits while their identity was
\end{abstract}

Date of Submission 15-9-2015

Date of Acceptance for Publication 3-5-2016

Conflict of Interest: None

Funding Source: None

Farooq M. ${ }^{1}$

Registrar, North Medical Ward, Mayo Hospital, Lahore

Saleem S. ${ }^{2}$

Assistant Professor of Medicine

Sargodha Medical College, Sargodha

Hussain I. ${ }^{3}$

Senior Registrar, Dept of Surgery

Sir Ganga Ram Hospital, Lahore

Sajid Abaidullah S. ${ }^{4}$

Professor of Medicine, KEMU/ Mayo Hospital, Lahore kept confidential. The demographic information of the patients like name, age, sex, height and weight were collected. Digital spirometer was used to perform pulmonary function tests. $\mathrm{FEV}_{1} / \mathrm{FVC}$ Ratio more than $80 \%$ or normal, was considered as restrictive defect and Ratio less than $80 \%$, was considered as obstructive defect. All collected information was s recorded on pre-designed Performa (attached). Effect modifying factors like duration of type 2 diabetes mellitus and smoking status (smoker and non smoker) were address through data stratification.

Results: In this study, we included one hundred and seventy type 2 diabetic patients. The mean age was $54.32 \pm 19.08$ years. There were $122(71.8 \%)$ males and $48(28.2 \%)$ females. The mean height was 161.59 $\mathrm{cm}$. The mean FVC was $107.78 \pm 20.31$. The mean $\mathrm{FEV}_{1}$ was $94.09 \pm 27.72$. The mean $\mathrm{FEV}_{1} / \mathrm{FVC} \%$ was $104.762 \pm 24.93$. In $28(16.5 \%)$ cases restrictive pathology was observed, $3(1.8 \%)$ cases had obstructive pathology and $139(81.8 \%)$ cases had normal lung function tests.

Conclusion: In this study we concluded that the target organ for diabetic injury was lung. It was responsible for restrictive diseases of lung. More research work required to rule out pathophysiologic mechanisms and clinical significance.

Key Words: Diabetes Mellitus, Pulmonary function test, Restrictive pulmonary dysfunction.

\section{Introduction}

Diabetes mellitus is a metabolic disorder because of insulin deficiency, inappropriate hyperglycemia generates or may be because of insulin resistance inside the body and insufficient insulin secretion to recompense with the body glucose. Type 2 Diabetes mellitus is 
dominant type and resulting from insulin resistance with compensatory insulin secretion dysfunction. $\mathrm{T}_{2} \mathrm{DM}$ is common in $>90 \%$ cases. ${ }^{1}$

In recent year it has been noticed with the evidences that pulmonary function of $\mathrm{T}_{2} \mathrm{DM}$ patients is reduced. Pulmonary factors associated with vital capacity warrant consideration as potential risk factors for insulin resistance and $\mathrm{T}_{2} \mathrm{DM}{ }^{2}{ }^{2}$ The Fremantle Diabetes Study showed that in start of study, among $125 \mathrm{~T}_{2} \mathrm{DM}$ candidates, 29 candidates had $\mathrm{FEV}_{1}<70 \%$ of predicted value and FVC $<80 \%$ of predicted value without previously documented pulmonary dusfunction. ${ }^{3}$

Lung functions are compromised in patients with $\mathrm{T}_{2} \mathrm{DM}$ like decrease in FVC, $\mathrm{FEV}_{1}$ and PEF as compared to non-diabetics. Stratification of results by duration of disease shows a dose - response effect on lung function parameters. ${ }^{4}$ Patients with $\mathrm{T}_{2} \mathrm{DM}$ have significantly lower $\mathrm{FVC}$ and $\mathrm{FEV}_{1}$ than those without $\mathrm{T}_{2} \mathrm{DM}$. FVC decreased in $\mathrm{T}_{2} \mathrm{DM}$ patients faster than non diabetics. ${ }^{5}$

Chronic complications of $\mathrm{T}_{2} \mathrm{DM}$ are decreased lung volumes and airflow limitation severity of which correlate with the exposure of glycemic level. After adjusting other risk factors, airflow restriction is predictor of death in T2DM. ${ }^{3}$ Expression of adhesion molecules increases due to hyperglycemia in $T_{2} D M$ patients. Lower pulmonary volumes in $\mathrm{T}_{2} \mathrm{DM}$ patients are due to compromised pulmonary microvasculature. Sensitive markers for endothelial activation and damage is adhesion molecules appearance in patients with $\mathrm{T}_{2} \mathrm{DM}^{6}{ }^{6}$

Pulmonary function tests have been proved to be affected by $\mathrm{T}_{2} \mathrm{DM}$. However no research work has been done in Pakistan so for. My study would like to record the frequency of pulmonary dysfunction in patients with $\mathrm{T}_{2} \mathrm{DM}$, so that early pulmonary function changes can be picked up and thus improve the patient care by strict glycemic control. We can reduce morbidity in patients with $\mathrm{T}_{2} \mathrm{DM}$ due to lung dysfunction by assuming lung as another target organ.

\section{Material and Methods}

This cross sectional study was conducted at Department of Medicine, King Edward Medical University Lahore from 01-02-2015 to 31-07-2015. One hundred and seventy non smoker ages $38-70$ years both male and female with type 2 Diabetes Mellitus, fulfilling the inclusion and exclusion criteria were included in the study through diabetic clinic of Mayo Hospital Lahore.
Smokers or patients with a history of acute or chronic respiratory disease, history of cirrhosis of liver and autoimmune diseases, history of occupational exposure like petrol pump workers or working in chemical or wood factory, neuromuscular or cardiovascular diseases or kyphoscoliosis, pectus excavatum and pectus carinatum and morbidly obese patients with BMI $>30$ $\mathrm{kg} / \mathrm{m}^{2}$ or patients having complaints of cough, sputum, or dyspnea were excluded. After taking informed consent, pulmonary function tests were performed. Patients were explained about the risks and benefits while their identity was kept confidential. The demographic information of the patients like name, age, sex, height and weight were collected. If $\mathrm{FEV}_{1} / \mathrm{FVC}$ Ratio is more than $80 \%$ or normal it was considered as restrictive defect and if this Ratio is less than $80 \%$ it was be considered as obstructive defect. All information was recorded on pre-designed Performa. All Data analyzed by using SPSS version 21.0 for windows. Variable like age was given as mean and standard deviation. Variables like sex and pulmonary dysfunction (restrictive) were given as frequency and percentage.

\section{Results}

The study included one hundred and seventy patients with the mean age of $54.32 \pm 19.08$ years. There were about $122(71.8 \%)$ males and $48(28.2 \%)$ females as shown in Table 1. The mean height was $161.59 \mathrm{~cm}$.

Table 1: Age distribution of patients according to Gender; $(n=170)$.

\begin{tabular}{|l|c|c|c|c|}
\hline Gender & $\begin{array}{c}\text { Mean Age } \\
\text { (Years) }\end{array}$ & SD & Minimum & Maximum \\
\hline Male & 54.30 & 6.49 & 38 & 70 \\
\hline Female & 54.39 & 6.52 & 40 & 70 \\
\hline
\end{tabular}

Table 2: Spirometry results and gender; $(\mathrm{n}=50)$.

\begin{tabular}{|c|c|c|c|}
\hline S. \# & Parameters & Males & Females \\
\hline 1. & $\begin{array}{c}\text { FVC liter / } \\
\text { minute }\end{array}$ & $109.28 \pm 20.22$ & $106.28 \pm 20.4$ \\
\hline 2. & $\begin{array}{c}\mathrm{FEV}_{1} \text { liter/ } \\
\text { minute }\end{array}$ & $94.5 \pm 28.07$ & $93.06 \pm 27.08$ \\
\hline 3. & $\begin{array}{c}\text { FEV } / \\
\text { FVC \% }\end{array}$ & $105.36 \pm 24.46$ & $103.25 \pm 26.29$ \\
\hline
\end{tabular}


The mean FVC was $106.28 \pm 20.4 \%$. The mean $\mathrm{FEV}_{1}$ was $94.09 \pm 27.72 \%$. The mean $\mathrm{FEV}_{1} / \mathrm{FVC} \%$ was $104.762 \pm 24.93$. Spirometry results according to gender are given in Table 2. In $28(16.5 \%)$ cases, restrictive pathology was observed, $3(1.8 \%)$ cases had obstructive pathology and $139(81.8 \%)$ cases had normal lung function tests as shown in Figure 2.

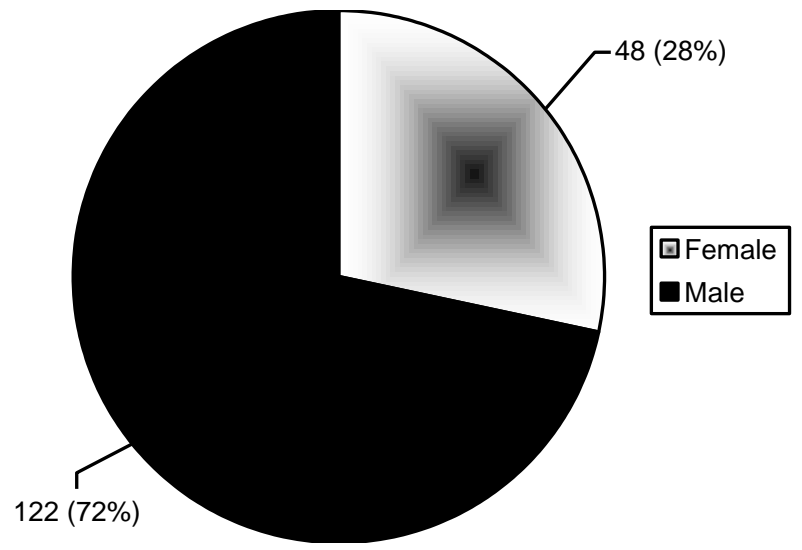

Figure 1: Pie Graph showing Gender Distribution.

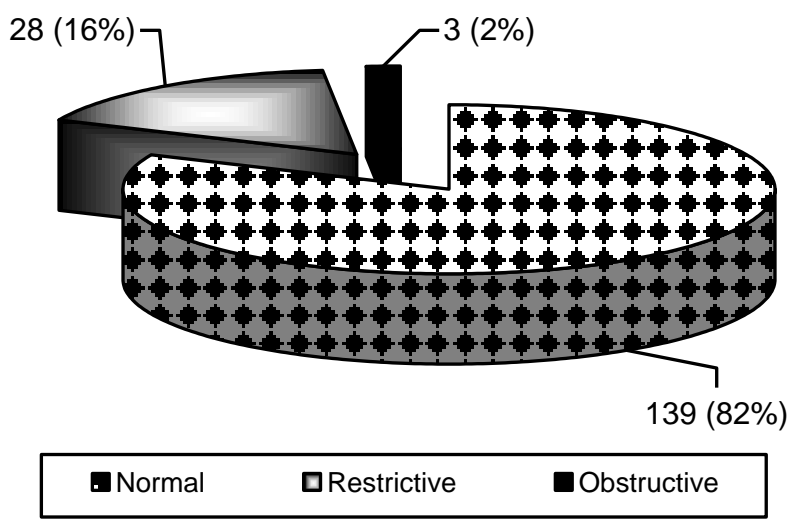

Figure 2: Pulmonary Dysfunction in Type II Diabetes Patients.

\section{Discussion}

Type 2 diabetes mellitus $\left(\mathrm{T}_{2} \mathrm{DM}\right)$ is a multisystem syndrome that affects almost every part of the body. It is base of all other associated problems of the human body. It is highly prevalent and become an important problem to be considered and has been widely discussed. $\mathrm{T}_{2} \mathrm{DM}$ also disturb the respiratory system but until now, very minor research work has been done in this regard.
The cross - sectional studies have shown that vital capacity is lower in $\mathrm{T}_{2} \mathrm{DM}$ as compared to non-diabetics. ${ }^{7}$ Our study included $170 \mathrm{~T}_{2} \mathrm{DM}$ patients, $16.5 \%$ were found to have restrictive pathology, $1.8 \%$ had obstructive pathology and $81.8 \%$ had normal lung function tests.

The results are similar to previously published data. Atherosclerosis Risk in Communities (ARIC) ${ }^{8}$ study of adults ages $45-64$, with hypothesis that $\mathrm{T}_{2} \mathrm{DM}$ is associated with reduced pulmonary function parameters. In cross - sectional analysis, middle - age $\mathrm{T}_{2} \mathrm{DM}$ patients have significantly lower pulmonary function parameters than predicted. These associations are catagorized by fasting glucose, $\mathrm{HbA}_{1} \mathrm{C}$, duration of diabetes and treatment. In prospective analysis, $\mathrm{FVC}$ decreased faster in $\mathrm{T}_{2} \mathrm{DM}$ patients as compared to nondiabetics. These correlations were independent of risk factors for lung function dysfunctions. This study, showed annual decrease of FVC by $58 \mathrm{ml} /$ year.

Results are consistent with cross - sectional studies which also have shown that diabetic patients have reduced $\mathrm{FEV}_{1}$ and $\mathrm{FVC}$ as compared to non-diabetics ${ }^{9,10}$ with respect to the duration of diabetes. Insulin treatment becomes mandatory, when diabetic patients have co-morbidities. While non diabetic patients have lower FVC and $\mathrm{FEV}_{1}$ due to high fasting glucose, hyperinsulinemia and insulin resistance.

Lange et al, ${ }^{11}$ followed 506 Danish adults in the Copenhagen City Heart Study for 15 years. Diabetic patients had lower FVC and FEV1 with difference of $>8 \%$ in $\mathrm{FVC}$ between diabetics and non-diabetics However, Diabetics had declined FVC $24 \mathrm{ml} /$ year in females and $39 \mathrm{ml} /$ year in males.

Davis et al, ${ }^{12}$ followed 125 Australian $\mathrm{T}_{2} \mathrm{DM}$ patients for duration of 7 years. FVC and FEV1 declined at annual rates of 68 and $71 \mathrm{ml} /$ year, respectively. $\mathrm{FVC}$ and $\mathrm{FEV}_{1}$ were declined in patients with higher baseline $\mathrm{HBA}_{1} \mathrm{C}$ with no non-diabetic control group.

Litonjua et al, ${ }^{13}$ conducted a case-control study in 352 patients with $\mathrm{T}_{2} \mathrm{DM}$ and 352 controls. This study showed that $\mathrm{T}_{2} \mathrm{DM}$ patients had lower $\mathrm{FEV}_{1}$ and $\mathrm{FVC}$. They had only $5.4 \mathrm{ml} /$ year decline after diagnosis of diabetes as compared to non-diabetics.

Primary mechanism lung dysfunction in diabetes remains unclear, Glycosylation of chest wall, thickening of basal lamina, ${ }^{14}$ increased susceptibility to respiratory infections and bronchial tree proteins were mechanism suggested in previous studies. However, hyperglycemia, inflammation and diabetes - related oxidative stress have association with muscular dysfunction. ${ }^{15}$ The pro-inflammatory master regulator 
molecules could mediate these effects which is further mediated by hyperglycemia. ${ }^{16,17}$

Other studies of pulmonary dysfunction in the prediabetic cases obscure causal extrapolations. Recent studies showed that compromised lung function is an independent factor of $\mathrm{T}_{2} \mathrm{DM}$ incidence. ${ }^{18}$ Cross sectional studies showed significant association in diabetes and lung functions as compared to prospective studies, These results showed that abnormalities in lung function precede diabetes and continue after onset of diabetes.

In a study conducted by Sharma B et al, ${ }^{20}$ a mixed restrictive - obstructive pattern of pulmonary dysfunction has been observed in $\mathrm{T}_{2} \mathrm{DM}$ patients which become more severe with course / duration of the disease and poor glycemic control. Strict glycemic control over 12 weeks is not adequate to progress this pulmonary dysfunction. Losartan (diabetes medication) with strict glycemic control does not improve the pulmonary function. Pulmonary dysfunction should be considered as a precise derangement induced by $\mathrm{T}_{2} \mathrm{DM}$. Further studies may elucidate whether this should be included as a long term complication of $\mathrm{T}_{2} \mathrm{DM}$. The role of strict glycemic control and losartan therapy on pulmonary function in diabetics with incipient nephropathy is another interesting aspect and needs further studies.

In a study done by Nakajima $\mathrm{K}$ et $\mathrm{al},{ }^{21}$ the most believable factor for the association between Restrictive Pattern and Metabolic syndrome is insulin resistance, an essential component that aggravates metabolic abnormalities. The association between pulmonary dysfunction and insulin resistance, and insulin deficiency has been verified by many investigators over several decades. ${ }^{158-21}$

This study has shown lung dysfunction, especially reduced vital capacity found in $\mathrm{T}_{2} \mathrm{DM}$ patients. Further research work required for pathophysiologic mechanisms and clinical importance of this association. Moreover, physicians must pay close attention to $\mathrm{T}_{2} \mathrm{DM}$ patients regarding their pulmonary functions. Cross sectional studies have been conducted in $T_{2} D M$ with respect to their pulmonary functions till today. Some $\mathrm{T}_{2} \mathrm{DM}$ patients have shown abnormalities of pulmonary function parameters, however more information of the association required to be sought out. The influence of duration of diabetes and glycemic control have major role in the development of restrictive pulmonary dysfunction through randomized trials.

\section{Conclusion}

In this study we conclude that the target organ for diabetic injury is lung. It is responsible for restrictive diseases of lung. More research work required to rule out pathophysiologic mechanisms and clinical significance.

\section{References}

1. Masharani U. Diabetes mellitus and hypoglycemia. Current medical diagnosis and treatment. 47th ed. New York: Mc Graw Hill, 2008: p. 1032-73.

2. Yeh HC, Punjabi NM, Warisq NY, Parkow JS, Duncan BB, Brancati FL. Vital capacity as predictor of incident type 2 diabetes. J Diabetes care, 2005; 28: 1472-9.

3. Davis WA,Kneuman M, Kendall P, Grange V, Davis TM. Glycemic exposure is associated with reduced pulmonary functions in type 2 diabetes. J Diabetes care, 2004; 27: 752-7

4. Mew SA, Al-Drees AM, Arif, Al-Rubean K. Lung functions in Saudi type 2 diabetic patients. J Saudi Med. 2006; 27: 338-43.

5. Yeh HC, Punjabi NM, Wang NY, Pankaw JS, Duncan $\mathrm{BB}, \mathrm{Cox} \mathrm{CE}$, et al. Cross sectional and prospective study of lung functions in adults with type 2 diabetes; the artroeclerosis risk in communities (ARIC) study. Diabetes care, 2008; 31: 741-6.

6. Boulbou MS, Gourgoulianis KI, Petinaki EA, Klisiaris VK, Maniatis AN, Molyvdas PA. Pulmonary function and circulating adhesion molecules in patients with diabetes mellitus. Can Respir J. 2003; 10: 259-64.

7. Marvisi M, Bartolini L, del Borrello P, Brianti M, Marani G, Guariglia A, Cuomo A: Pulmonary function in non-insulin - dependent diabetes mellitus. Respiration, 2001; 68: 268-72.

8. Yeh H-C, Punjabi NM, Wang N-Y, Pankow JS, Duncan BB, Cox CE et al. Cross - sectional and prospective study of lung function in adults with type 2 diabetes: the Atherosclerosis Risk in Communities (ARIC) Study. Diabetes Care, 2008; 31: 741-6.

9. Lawlor DA, Ebrahim S, Smith GD: Associations of measures of lung function with insulin resistance and type 2 diabetes: findings from the British Women's Heart and Health Study. Diabetologia. 2004; 47: 195203.

10. Lange P, Parner J, Schnohr P, Jensen G: Copenhagen City Heart Study: longitudinal analysis of ventilatory capacity in diabetic and non-diabetic adults. Eur Respir J. 2002; 20: 1406-12.

11. Borch - Johnson K, for DECODE study group, on behalf of the European Diabetes Epidemiology Study Group. "Will new diagnostic criteria for diabetes mellitus change phenotype of patients with diabetes?" Reanalysis of European Epidemiological Data. Br Med J. 
1998; 32: 317-75.

12. Vogt BW, Schleicher ED, Wieland OH. e-amino-lysine - bound glucose in human tissue obtained at autopsy. Diabetes, 1982; 31: 1123-27.

13. Litonjua AA, Lazarus R, Sparrow D, Demolles D, Weiss ST: Lung function in type 2 diabetes: the Normative Aging Study. Respir Med. 2005; 99: 1583-90.

14. Weynand B, Jonckheere A, Frans A, Rahier J: Diabetes mellitus induces a thickening of the pulmonary basal lamina. Respiration, 1999; 66: 14-9.

15. Niedowicz DM, Daleke DL: The role of oxidative stress in diabetic complications. Cell Biochem Biophys. 2005; 43: 289-330.

16. Patti ME: Gene expression in the pathophysiology of type 2 diabetes mellitus. Curr Diab Rep. 2004; 4: 17681.

17. Dandona P, Aljada A, Chaudhuri A, Mohanty P, Garg R: Metabolic syndrome: a comprehensive perspective based on interactions between obesity, diabetes, and inflammation. Circulation, 2005; 111: 1448-54.

18. Engstrom G, Janzon L: Risk of developing diabetes is inversely related to lung function: a population - based cohort study. Diabet Med. 2002; 19: 167-70.

19. Cefalu WT: Concept, strategies, and feasibility of noninvasive insulin delivery. Diabetes Care, 2004; 27: 239-46.

20. Sharma B, Daga MK, Tiwari N, Kaushik M. Pulmonary Dysfunction in Type 2 Diabetes Mellitus Patients With Incipient Diabetic Nephropathy and Effect of Glycemic Control and Losartan Therapy on Pulmonary Function, 2003; 124 (4): 162.

21. Nakajima K, Kubouchi Y, Muneyuki T, Ebata M, Eguchi S, Munakata H. A Possible Association between Suspected Restrictive Pattern as Assessed by Ordinary Pulmonary Function Test and the Metabolic Syndrome. Am. J. Epidemiol., December 15, 2008; 158 (12): 1171-1181. 